\title{
Insights into temporal patterns of hospital patient safety from routinely collected electronic data
}

\author{
Blanca Gallego ${ }^{*}$, Farah Magrabi, Oscar Perez Concha, Ying Wang, Enrico Coiera \\ From HISA Big Data in Biomedicine and Healthcare 2013 Conference \\ Melbourne, Australia. 18-19 April 2013
}

\begin{abstract}
Background: The last two decades have seen an unprecedented growth in initiatives aimed to improve patient safety. For the most part, however, evidence of their impact remains controversial. At the same time, the healthcare industry has experienced an also unprecedented growth in the amount and variety of available electronic data.
\end{abstract}

Methods: In this paper, we provide a review of the use of routinely collected electronic data in the identification, analysis and surveillance of temporal patterns of patient safety.

Results: Two important temporal patterns of the safety of hospitalised patients were identified and discussed: long-term trends related to changes in clinical practice and healthcare policy; and shorter term patterns related to variations in workforce and resources. We found that consistency in reporting is intrinsically related to availability of large-scale, fit-for-purpose data. Consistent reported trends of patient harms included an increase in the incidence of post-operative sepsis and a decrease in central-line associated bloodstream infections. Improvement in the treatment of specific diseases, such as cardiac conditions, has also been demonstrated. Linkage of hospital data with other datasets provides essential temporal information about errors, as well as information about unsuspected system deficiencies. It has played an important role in the measurement and analysis of the effects of off-hours hospital operation.

Conclusions: Measuring temporal patterns of patient safety is still inadequate with electronic health records not yet playing an important role. Patient safety interventions should not be implemented without a strategy for continuous monitoring of their effect.

\section{Introduction}

Administrators, healthcare providers and researchers struggle to decide which practices are most cost-effective in the improvement of patient safety. A major reason behind this problem is the fragmented and specialised nature of modern healthcare systems. This fragmentation occurs at different levels, among inpatient, out-patient and general practice care as well as among hospital wards. This results in poor information flows, disjointed care and inadequate boundaries of legal and financial responsibilities, all of which negatively influence quality of care and patient safety, and make it

\footnotetext{
* Correspondence: b.gallego@unsw.edu.au

Centre for Health Informatics, Australian Institute of Health Innovation, University of New South Wales, Kensington NSW 2052, Australia
}

harder to understand and measure it [1,2]. Furthermore, hospitals, like any other organisation, need to adapt to changes in their environment, such as ageing population, more sophisticated technologies, temporal disease patterns, variations in workforce and changes in funding [3]. Appropriate continuous measurement of temporal patterns of patient safety in and beyond the hospital has become essential to inform hospital patient safety strategies.

With the growing availability of electronic routinely collected data inside hospitals and across the healthcare system, we have the opportunity to track patient safety over time and explore its temporal 'rhythms'. One of the criticisms of the use of routinely collected data for measuring quality of care is the fact that data may not be fit 
for purpose. Many measure gaps have been identified e. g. related to patient functional status, patient at the end of life, continuity of care, and some important process measures. Nevertheless, the continuous growth of the adoption of electronic health records (EHRs), new ways of sharing data via distributed data networks, together with better standardisation will slowly make the task of measuring patient safety easier.

In this paper we provide a review of the role of administrative datasets (including linked data), claims datasets, registries, surveillance systems and EHRs, in the detection and analysis of temporal patterns in hospital patient safety. We identified two important aspects in the temporal dynamics of healthcare delivery in hospitals, which are intrinsically linked to patient safety: (a) Sustained changes in processes of care and patient outcomes following the adoption of new technologies or new policies; these changes are often slow, taking place on the order of months or years. (b) Temporal variations related to workforce and resource patterns including weekend and after-hours hospital operation, hospital shifts and yearly influx of new graduates; this dynamics encompasses hourly, daily or monthly changes. A summary of our findings is displayed in Table 1.

\section{Measuring hospital patient safety using routinely collected electronic data}

The oldest and most widely-used measure of patient safety is mortality. Without appropriate context, however, this important patient outcome is a crude measure of safety since it does not provide a complete picture. Indeed, the use of hospital standardised mortality ratios as a measure of quality of care has been heavily criticised $[4,5]$. Part of the problem stems from our inability to predict when death was preventable and, in particular, when patients are at the end of their natural life $[4,6]$. Nevertheless, for specific subpopulations and in conjunction with other relevant information, mortality remains an important outcome measure of safety. Other

Table 1 Summary of patient safety related temporal patterns measured by routinely collected data

Long term trends:
Effect of changes in clinical
practice and healthcare policy

Datasets

- Hospital
administrative data
(mostly using PSI)
- Registries (e.g.
cardiac-related)
- National Surveillance
systems (e.g.
nosocomial infections)
- Pharmacy and
clinical laboratory data
- Electronic Health
Records

Records
- Sustained decrease in central line-associated bloodstream infections $[62,63,65]$

- Sustained increase in post-operative sepsis

[51-55] and post-operative thromboembolism [51-53]

- Sustained improvement in treatment and

- Surgical safety checklist for reduction of surgical AEs[68].

- Subglottic secretion drainage for the prevention of ventilator-associated pneumonia [69].

- Sterile barriers and antibiotic-impregnated catheters for the reduction of catheter-related blood stream infections [66]

Hourly, weekly and monthly variations: Effect of changes in workforce and resources

$\begin{aligned} \text { Weekend and after-hours effect } & \text { - Hospital } \\ & \text { administrative data } \\ & \cdot \text { Registries (e.g. death, } \\ & \text { cardiac surgery) }\end{aligned}$

- Increased in-hospital mortality for weekend admissions among some patient groups 77

- Increased 7 day post-admission (in-hospital and post-discharge) mortality for weekend admissions for some patient groups [80]

- Weekend and after-hours AMI admissions less likely to receive timely cardiac procedures $[81,83]$ - Only $5 \%$ of six urgent procedures were performed on the weekend [87]

July effect
- Increase in mortality and decrease in efficiency after new residents after influx of junior residents [96]

- Increased LOS and mortality rates in teaching hospitals related to residency turnover [97] - Significant spike in fatal medication errors during July [98] 
outcomes of care that can be easily extracted from administrative datasets, and that have been correlated with patient harm are hospital length of stay [7] and unplanned hospital readmissions, particularly in relation to drug adverse events [8]. Linkage of hospital administrative data with death registries, emergency department visits data, public and private claims data, and other administrative databases have proved useful to measure mortality post-discharge, re-admissions, or history of previous hospitalisations.

The patient outcome measures most closely associated to patient safety are potentially preventable adverse events, as defined by the Institute of Medicine [9]. Traditionally, the gold standard for reporting these patient harms is through manual review of medical records by expert clinicians (see review [10]). This is a labour intensive job that requires at least two independent evaluators, who often present low to moderate rates of agreement. In order to facilitate this task, special methods to systematically review medical records to screen for 'triggers' of potential patient harm have been developed. The most commonly used is the Global Trigger Tool [11].

A more cost-effective method of detecting patient harm events can be achieved using routinely electronically captured information. Automated screening using administrative and claim records searches for adverse events among diagnosis and procedural codes. For example, the Medicare Patient Safety Monitoring System [12] is a US surveillance system that uses administrative and inpatient Medicare discharges to screen for adverse events. Medical records of the selected patients are then reviewed by experts, reducing the cost per chart reviewed. One drawback of this system is the potential for missing adverse events. The Agency for Healthcare Research and Quality also developed a set of Patient Safety Indicators (PSI) to recognise patient safety incidents from administrative data [13,14]. The limitations of administrative data, in general, and of the PSIs in particular, have been pointed out in several studies [15]. Mostly, administrative coding was generated for the purpose of reimbursement, and therefore lacks clinical content and context. Some adverse events are poorly represented by PSIs, which have been found to have positive predictive values (PPV) ranging from $28 \%$ for postoperative hip fracture to $87 \%$ for postoperative wound dehiscence [16]. Nevertheless, the creation of newer codes (e.g. [17]) and, in particular, of present-onadmission (POA) flags (to discriminate between preexisting and hospital-acquired conditions) $[18,19]$ have increased the validity of these measures.

Some of the limitations encountered when using administrative data alone can be reduced when combined with other electronic datasets, such as pharmacy and clinical laboratory data. These additional sources of information increase the knowledge of illness severity and can signal specific adverse events such as sudden adverse drug reactions $[20,21]$. Another useful source of routinely collected information easily linked to administrative data and now also implemented in electronic format is discharge summaries. The clinical narratives of discharge summaries have proven useful in increasing the specificity of adverse event detection tools [22,23]. Because a significant percentage of patient safety events take place post-discharge [24] or in an outpatient setting [25], linking datasets across types of care are needed to measure the full extent of the effect of hospital adverse events.

Eventually, information integrated in EHRs will provide the ideal source for automated detection of patient safety events. The use of EHRs allows better identification of clinically relevant patient groups $[20,21,26,27]$ and has the potential to greatly improve the cost-effectiveness of audit processes [21]. Also, it provides a way to analyse the health care system as a whole and not as independent health care units. Already, automated identification of drug adverse events and hospital-acquired infections has been implemented using information technology (see e.g. [28]). Furthermore, in contrast to administrative and claims data, EHRs are recorded in near real time allowing for earlier surveillance of patient safety [29]. Although levels of adoption of EHRs are still low $[30,31]$, and the quality of EHRs today is highly variable [32], as the secondary use of EHRs becomes more prevalent, and appropriate standards are introduced and validated, we expect availability and quality of EHR data to improve.

National surveillance systems and registries offer highquality long-term counts of specific patient safety events. One of the oldest running surveillance systems of hospital adverse events is the Centers for Disease Control and Prevention's National Nosocomial Infections Surveillance (NNIS) system [33] (now National Healthcare Safety Network), established in 1970. Data is collected using standardised protocols and it is classified by hospital ward, associated clinical procedure or device, and infection type using information from pathology. Registries were designed to collect patient-level, fit-for-purpose, data around specific interventions or conditions in order to be able to compare institutions, devices/procedures and patients, as well as to monitor temporal trends. The most ubiquitous registries relate to cardiac surgery and cardiac interventions [34].

Incident reporting systems, where hospital personnel voluntarily and confidentially report incidents, represent another repository of patient safety events. Data from established large incident reporting systems usually contain a structured taxonomy that classifies the patient safety event together with free narrative describing the 
event [35]. Although this data represents only a very small (under 5\%) and biased sample (mainly identification, falls and medication errors) of actual patient safety events, it provides complementary information about near misses and the clinical context and contributing factors leading to patient harm [36,37]. Studies of incidents reported by patients after hospitalisation suggest that patient reports are generally reliable $[38,39]$. However, preferred ways of soliciting patient information still involve resource-consuming methods such as inperson or phone interviews. Adding questions regarding adverse events to current electronic hospital patient surveys, or extending existing incident report systems to patients are some of the cost-effective ways to build these important consumer databases. It is also possible to query and analyse electronic datasets of medical-malpractice claims. This data also represents a very small and biased fraction of all the adverse events related to medical negligence $[37,40]$.

Due to limitations in measuring patient harms, process of care measures have been included as additional indicators of patient safety, particularly in the context of evaluation of hospital performance [41]. Process measures should have a demonstrable causal relation with multiple patient outcomes. Examples of evidence-based process measures are antibiotic prophylaxis before surgery [42] and aspirin at arrival for patients with acute myocardial infarction [43]. Most processes of care measures are only captured in medical records or registries.

The analysis of large sets of routine clinical data plays an important role in post-marketing surveillance of harmful or ineffective treatment plans. Many adverse events associated with drugs or devices are too infrequent to be detected in randomised clinical trials, or may affect patient populations with specific co-morbidities, often excluded from experimental studies. Observational studies using large routine clinical datasets can also generate hypotheses, which can guide clinical trial design, thus providing a safer and more efficient way of generating medical evidence.

Temporal trends: the effect of changes in clinical practice and healthcare policy

Little has been said regarding the sustained widespread effects on patient safety that arise from changes in clinical practice and healthcare policy. Observational studies designed to analyse the effect of safety interventions often report short-term changes in local settings and are sometimes controversial [44-47]. Reasons for this poor surveillance include the need to balance sustained improvement versus the possibility of improvement trends unrelated to the intervention, lack of good quality data that is fit for purpose, and the complexity in evaluating patient safety practice $[48,49]$. On the other hand, studies analysing observed long-term, large-scale temporal trends in processes of care and patient outcomes cannot easily unravel the contribution of specific interventions; and temporal electronic data of detailed adoption and implementation of new clinical practices and policies is generally lacking. An additional difficulty arises from the need to account for changes in recording and reporting methods over time.

The temporal evolution in the incidence of hospital patient harm events has been measured using review of medical records with the Global Trigger Tool (GTT) [50]; PSIs [51-55] and diagnostic codes [56] from administrative datasets; disease-specific performance measures and selected outcomes collected from registries [57,58] and national surveillance programs [59-63] and malpractice claims [64].

While Landrigan et al found no evidence of widespread improvement between 2002 and 2007 in 10 North Carolina hospitals [50]; studies using PSIs and larger inpatient datasets found significant (albeit sometimes differing) temporal trends. For example, studies of approximately 1,000 US hospitals found a decreased trend of iatrogenic pneumothorax between 1995 and 2000 [51] and between 1998 and 2007 [53]. On the other hand, study [52] described an increased trend on the same patient harm in 108 Veteran's Health hospitals from 2001 to 2004. Post-operative sepsis and postoperative venous thromboembolism events were found to increase in all above studies. The increase in the rate of post-operative sepsis has been confirmed by other studies [54,55]. This has also been found by the authors of this review among hospitals in New South Wales (NSW), Australia (see Figure 1).

Reasons behind these observed changes in the rates of specific adverse events are not usually properly

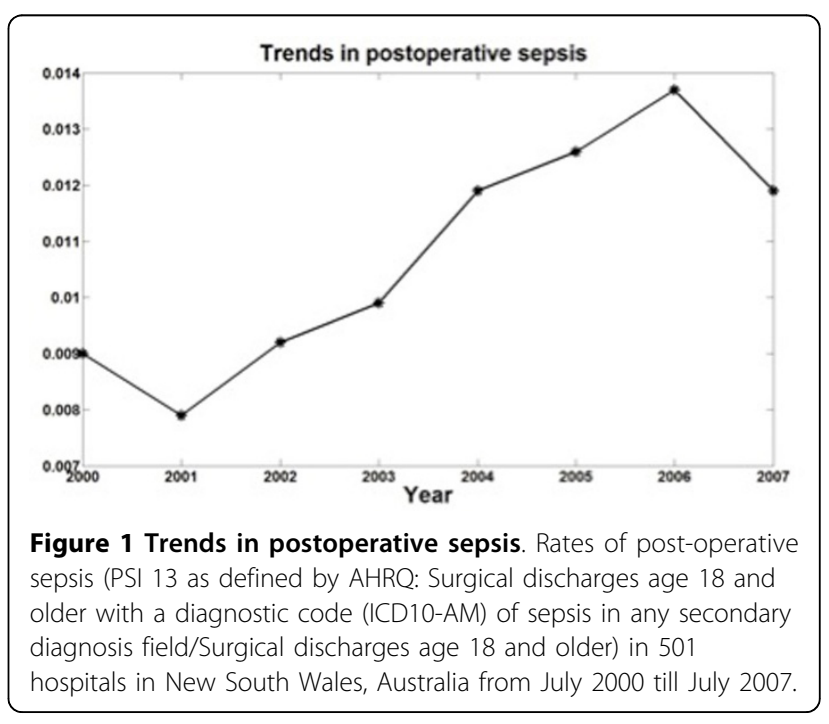


elucidated and discussed in the literature. It is believed that sustained changes are achieved via multistep, multilevel efforts involving clinicians, regulatory agencies and hospital administrators alike. A good example of a successful sustained reduction in patient harm is the prevention of bloodstream infections. Trends in central line-associated bloodstream infections in the US show a marked decrease since the late $90 \mathrm{~s}[62,63,65]$. Pronovost and colleagues [66] describe the effort behind this success as a combination of measurement, dissemination and mobilisation across many stakeholders. Evidence on the history of the evolution of safety in hospitals also indicates that the greatest safety gains often come from the introduction and subsequent widespread adoption of safer drugs and procedures.

Analyses of performance indicators for selected conditions have found consistent improvement among a large random sample of inpatient datasets in the US in 2001 as compared to 1998 [60]; as well as across 3,000 accredited US hospitals in 2004 as compared to 2002 [61]. In particular, treatment of cardiac conditions, such as acute myocardial infarction, has undergone numerous welldocumented changes in the last couple of decades, which have significantly improved the safety of patients suffering from these conditions $[34,58,59,61,67]$. Improvement was observed in relation to the adoption of new techniques (e.g. use of coronary stent instead of atherectomy devices) and evidence-based recommendations (e.g. rapid administration of thrombolytic therapy), as well as in patient outcomes (e.g. length of stay, death).

There is no lack of studies relating specific safety interventions to improvements in the reduction of harm. A discussion on evidence-based patient safety practices can be found at [44]. The best understood patient safety practices with higher strength of evidence relate to focus interventions aimed at reducing specific patient harms. Examples of successful interventions include the surgical safety checklist [68], which has been linked to a significant reduction in death and complications associated with non-cardiac surgery across the world; the use of subglottic secretion drainage for the prevention of ventilator-associated pneumonia [69]; and the use of sterile barriers and antibiotic-impregnated catheters for the reduction of catheter-related blood stream infections [66]. Analyses of the impact of more general patient safety interventions are often controversial or inconclusive. For example, some of the more recent, across the board, quality of care interventions in the US: pay for performance [70,71], restriction of specific procedures to centers of excellence [56,72], and work hour regulations [47,73], lack positive conclusive evidence.

Examinations of trends in patient safety require the use of large, fit-for-purpose data, such as that extracted from longitudinal medical records. Available temporal trends show a mixed picture with improvement in the treatment of some conditions and worsening or nochange in others. There have been extensive efforts on improving patient safety across the world. However, due to limitations in measures and data sources, the effects of most of these efforts remain unclear.

\section{Hourly, weekly and monthly variations: the effect of changes in workforce and resources}

When patients go to hospital, they expect to receive high levels of safety and care at all times. However, using routinely collected electronic data, several studies have demonstrated the existence of higher risk of death and adverse events at specific times of the day, days of the week, and months of the year. These periods of decreased safety have been related to both changes in staff numbers and composition, as well as lack of access to specialised clinical facilities.

It is well known that hospitals during weekdays between approximately 8 am and $6 \mathrm{pm}$ and hospitals during off-hours (weekends and after-hours) are two very different clinical environments [74]. Off-hours hospitals have only a small percentage of administrative and clinical teams, with no senior managers, almost no consultants or specialists and significantly lower nurse-topatient ratios. These differences in staff composition and numbers are known to worry both junior doctors as well as hospital chief executive officers. Hospital residents perceive excessive work hours, inadequate supervision and problems with handoffs as the most common reasons for mistakes [75]. Similarly, nurses perceive personal neglect, heavy workload and changes in staff as the main factors in medication errors [76]. The relationship between staff numbers, particularly nurse staffing, and patient outcomes has also been documented (see e. g. [77]). On the other hand, access to some clinical facilities, such as diagnostic testing and specialised theaters, is also often not available outside normal operating hours. This reality has made researchers hypothesise a lower quality of care during weekends and after-hours, particularly for conditions that require complex immediate care outside emergency departments and intensive care units [78].

Using large hospital administrative datasets, researchers have found that mortality among some patient groups admitted on weekends via emergency departments is higher than for those patients admitted on weekdays (see Figure 2); and that there are no groups for which weekend admission is safer $[79,80]$. This phenomenon has also been demonstrated in studies focusing on special conditions (see e.g. [78,81-84]). In some of these studies, linkage with mortality registries allowed for the analysis of deaths post-discharge [80-84]. In order to help discriminate between lower quality of care 


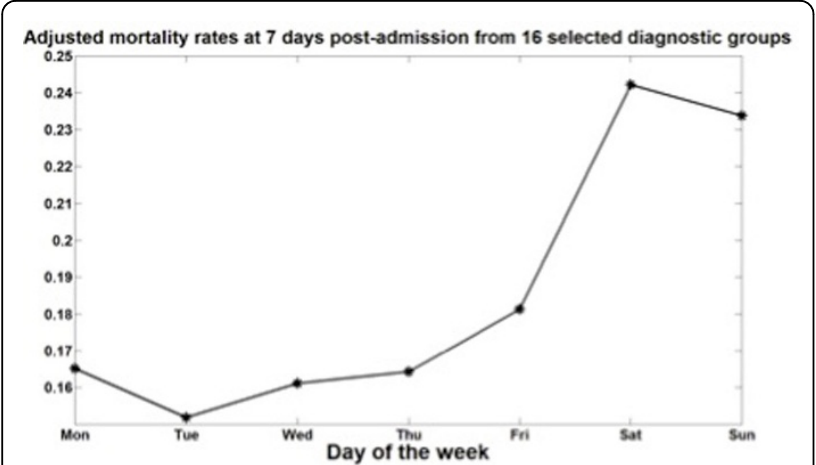

Figure 2 Adjusted mortality rates at 7 days post-admission from 16 selected diagnostic groups. Mortality rates at 7 days postadmission for 16 selected diagnostic groups within emergency admissions to 501 hospitals in New South Wales, Australia between July 2000 and July 2007. Mortality rates were adjusted by sex, age, and Charlson morbidity index. Diagnostic groups were selected as those for which there was a statistically significant 'weekend effect' (see [80]).

and sicker patients presenting to emergency departments in the weekend, Perez-Concha et al looked at the survival curves associated with various patient groups during one week post-admission; they found that for some patients (e.g. patients with heart conditions), failing to provide immediate care during the weekend appeared to be the reason behind the increased risk in mortality, while for others (e.g. cancer patients) the observed 'weekend effect' was likely to be due to differences in patient condition [80]. Linking births and deaths certificates has shown increase in the risk of neonatal death after-hours $[85,86]$. Other outcomes such as length of stay [87], and re-admissions [81] have also been observed to increase for emergency weekend admissions. Errors in ordering medications during the overnight period have also found to increase, particularly by postgraduate year 1 doctors [88].

When looking at the 'weekend effect' more closely, researchers have found that there are measurable differences in patient treatments. In particular, it has been observed that the incidence and timing of important interventional procedures differs for weekend vs. weekday patients. For example, off-hours patients presenting with acute myocardial infarction are less likely to receive immediate cardiac procedures [81,83]; and experience substantially longer door-to-balloon times [89]. Indeed, Kostis et al [83] found that statistically significant differences in 30 days mortality became nonsignificant after adjusting for invasive cardiac procedures. Similarly Bell et al [87] analysed time to six prespecified procedures among more than 100,000 emergency admissions in Canada, and found that only $5 \%$ of urgent procedures were performed on the weekend. Delays in interventional procedures have been independently related to infection complications, length of stay and mortality $[90,91]$.

The effect of weekends and evenings has also been found when comparing the outcomes from elective surgery among days of the week [92,93]; for patients suffering from an in-hospital cardiac arrest [94] and for adults admitted to and discharged from intensive care [95].

Another phenomenon observed using routinely collected data is the relationship between patient outcomes and the cyclic rotation of trainee doctors, which takes place in teaching hospitals. In the Northern Hemisphere the influx of new or junior residents occurs in July, and therefore the existence of this period of observed decreased patient safety has been coined the 'July effect'. Researchers hypothesise that this staff turnover disrupts established doctor teams abruptly decreasing the average experience of the workforce. Young and colleagues performed a review of the literature regarding this phenomenon in 2011 [96]. They concluded that, in general, existing studies demonstrate an increase in mortality and a decrease in efficiency (reported as length of stay, duration of procedure and hospital charges) related to the end of the year changeovers. The 'July effect', like the 'weekend effect', does not affect all patient groups and a substantial degree of heterogeneity among studies has been found; however, its evidence is generally weaker. One of the largest studies of the effect of cohort turnover involved roughly $20 \%$ of all US hospitals for a period of 5 years [97]. By comparing temporal trends of teaching vs non-teaching hospitals, the authors found increased average length of stay and mortality rates related to residency turnover. Another large study including over 60 million death certificates and more than 200,000 medication errors, found a significant spike in fatal medication errors at medical institutions during July [98].

Evidence of the impact of differences in standard of care, such as out-of-hours care, could not have been revealed without the use of large routinely collected electronic data. More informative data and further research are needed to unravel the causes behind these periods of decreased safety and provide appropriate solutions.

\section{Discussion}

In this paper we provide a review of the current use of routinely collected electronic data to identify and analyse temporal patterns of hospital patient safety. We found that the science of measuring patient safety is still not properly advanced and surrounded by controversy. The gold standard of counting patient harms is still manual review of medical records, and use of full EHRs for this purpose is far from widespread. This is an important problem, since it is well known that trust in measures and 
the measurement process facilitate the use of the recorded information for training and improvement. For those situations in which there is suitable large-scale temporal data, it is much easier to find consistent trends. One example is the observed decrease in central lineassociated bloodstream infections in the US, captured by the national surveillance program on nosocomial infections.

Assessing the impact of patient safety interventions is currently poorly done. Most studies only report pre and post intervention effects in local settings without any further monitoring of sustained change. Often these reports are controversial. We propose that interventions should always be implemented together with a strategy for continuous monitoring of the target patient outcome.

Data linkage has proved useful in the unravelling of important temporal aspects of patient safety; for example, death and birth registries, data containing the day and time of interventional procedures and clinical datasets that help to better determine the illness severity of patients. However, some useful patient-safety related datasets, such as information about staffing numbers in each hospital shift and information about locum personnel, are mostly unavailable. A notable exception is the case of some hospitals in Massachusetts which provide voluntary unit-by-unit reports on caregiver staffing levels updated on an annual basis for over 750 hospital units including emergency departments [99].

Some of the temporal patterns discussed in this review warrant further investigation. A worrisome increase in the incidence of post-operative sepsis, for example, has been found in several studies. New evidence on the negative effect of weekend and after-hours hospital operation has made researchers argue about what should be the most cost-effective way of improving offhours hospital care [81]. If the cause of the 'weekend effect' is understaffing then the strategy should be to regulate workforce. If, however, the cause is inappropriate treatment (such as delays to surgery) not related to staffing numbers then a more cost-effective strategy could be rewarding good off-hours performance. Information technology can also help reducing the gap between the 'normal' and the 'off-hours' hospital by creating safety nets and providing information for junior doctors when senior staff are not present.

Analyses of routinely collected electronic records provide essential insights into temporal patterns of hospital patient safety. They reveal the existence of non-clinical temporal patterns related to hospital workflow and allow for the monitoring of the effect of patient safety interventions. However, there are still important information gaps with respect to both patients (clinical and social status) as well as hospitals (staffing numbers, availability of specialised facilities). The use of integrated EHRs will be important to fill in some of these gaps and provide more meaningful measures of safety.

\section{Funding and ethics statement}

This work was funded by National Health and Medical Research Council (NHMRC) Program Grant 568612, and Project Grant 1045548; and approved by the NSW Population and Health Services Research Ethics Committee and the UNSW Human Research Ethics Committee. Its contents are the responsibility of the authors and their institutions and do not reflect the views of the NHMRC.

\section{Competing interests}

The authors declare that they have no competing interests.

\section{Declarations}

Publication costs were funded by NHMRC Program Grant 568612 This article has been published as part of Health Information Science and Systems Volume 3 Supplement 1, 2015: Proceedings of the Health Informatics Society of Australia Big Data Conference (HISA 2013). The full contents of the supplement are available online at http://www.hissjournal. com/supplements/3/S1/

Published: 24 February 2015

\section{References}

1. Wachter RM: The end of the beginning: patient safety five years after "To Err Is Human.". Health Affairs 2004, 23(11):534-545.

2. Pronovost PJ, Miller MR, Wachter RM: Tracking progress in patient safety. JAMA: the journal of the American Medical Association 2006, 296(6):696-699.

3. Stephen W, Nigel E, Bernd R: Investing in hospitals of the future World Health Organization; 2009.

4. Penfold RB, Dean S, Flemons W, Moffatt M: Do hospital standardized mortality ratios measure patient safety? HSMRs in the Winnipeg Regional Health Authority. Healthc Pap 2008, 8(4):8-24.

5. Mohammed MA, Deeks JJ, Girling A, Rudge G, Carmalt M, Stevens AJ, Lilford RJ: Evidence of methodological bias in hospital standardised mortality ratios: retrospective database study of English hospitals. BMJ: British Medical Journal 2009, 338.

6. Carlet J, Thijs LG, Antonelli M, Cassell J, Cox P, Hill N, Hinds C, Pimentel JM, Reinhart K, Thompson BT: Challenges in end-of-life care in the ICU. Intensive care medicine 2004, 30(5):770-784.

7. Zhan C, Miller MR: Excess length of stay, charges, and mortality attributable to medical injuries during hospitalization. JAMA: the journal of the American Medical Association 2003, 290(14):1868-1874.

8. Winterstein AG, Sauer BC, Hepler CD, Poole C: Preventable drug-related hospital admissions. The Annals of pharmacotherapy 2002, 36(7/8):1238-1248.

9. Kohn L, Corrigan J, Donaldson M: To Err is Human. Building a Safer Health System. Committee on Quality of Health Care in America. Washington, DC: Institute of Medicine. Academy Press; 1999.

10. de Vries EN, Ramrattan MA, Smorenburg SM, Gouma DJ, Boermeester MA: The incidence and nature of in-hospital adverse events: a systematic review. Quality and Safety in Health Care 2008, 17(3):216-223.

11. Classen DC, Resar R, Griffin F, Federico F, Frankel T, Kimmel N, Whittington JC, Frankel A, Seger A, James BC: 'Global trigger tool'shows that adverse events in hospitals may be ten times greater than previously measured. Health Affairs 2011, 30(4):581-589.

12. Hunt DR, Verzier N, Abend SL, Lyder C, Jaser LJ, Safer N, Davern P: Fundamentals of Medicare patient safety surveillance: intent, relevance, and transparency. DT/C Document 2005.

13. Miller MR, Elixhauser A, Zhan C, Meyer GS: Patient Safety Indicators: using administrative data to identify potential patient safety concerns. Health Services Research 2001, 36(6 Pt 2):110. 
14. McDonald KM, Romano PS, Geppert J, Davies SM, Duncan BW, Shojania KG, Hansen A: Measures of patient safety based on hospital administrative data-the patient safety indicators. 2002.

15. Zhan C, Miller M: Administrative data based patient safety research: a critical review. Quality and Safety in Health Care 2003, 12(suppl 2):ii58-ii63.

16. Rosen AK, Itani KM, Cevasco M, Kaafarani HM, Hanchate A, Shin M, Shwartz M, Loveland S, Chen Q, Borzecki A: Validating the patient safety indicators in the Veterans Health Administration: do they accurately identify true safety events? Medical care 2012, 50(1):74-85

17. Sadeghi B, White RH, Maynard G, Zrelak P, Strater A, Hensley L, Cerese J, Romano P: Improved Coding of Postoperative Deep Vein Thrombosis and Pulmonary Embolism in Administrative Data (AHRQ Patient Safety Indicator 12) After Introduction of New ICD-9-CM Diagnosis Codes. Medical care 2013.

18. Glance LG, Osler TM, Mukamel DB, Dick AW: Impact of the present-onadmission indicator on hospital quality measurement: experience with the Agency for Healthcare Research and Quality (AHRQ) Inpatient Quality Indicators. Medical care 2008, 46(2):112-119.

19. Houchens RL, Elixhauser A, Romano PS: How often are potential patient safety events present on admission? Joint Commission Journal on Quality and Patient Safety 2008, 34(3):154-163.

20. Shahian DM, Silverstein T, Lovett AF, Wolf RE, Normand S-LT: Comparison of clinical and administrative data sources for hospital coronary artery bypass graft surgery report cards. Circulation 2007, 115(12):1518-1527.

21. Pine M, Sonneborn M, Schindler J, Stanek M, Maeda JL, Hanlon C Harnessing the power of enhanced data for healthcare quality improvement: lessons from a Minnesota Hospital Association Pilot Project. Journal of healthcare management/American College of Healthcare Executives 2011, 57(6):406-418, discussion 419-420.

22. Murff HJ, Forster AJ, Peterson JF, Fiskio JM, Heiman HL, Bates DW: Electronically screening discharge summaries for adverse medical events. Journal of the American Medical Informatics Association 2003, 10(4):339-350.

23. Melton GB, Hripcsak G: Automated detection of adverse events using natural language processing of discharge summaries. Journal of the American Medical Informatics Association 2005, 12(4):448-457.

24. Forster AJ, Clark HD, Menard A, Dupuis N, Chernish R, Chandok N, Khan A, van Walraven C: Adverse events among medical patients after discharge from hospital. Canadian Medical Association Journal 2004, 170(3):345-349.

25. Thomsen LA, Winterstein AG, Søndergaard B, Haugbølle LS, Melander A: Systematic review of the incidence and characteristics of preventable adverse drug events in ambulatory care. The Annals of pharmacotherapy 2007, 41(9):1411-1426.

26. Jollis JG, Ancukiewicz M, DeLong ER, Pryor DB, Muhlbaier LH, Mark DB: Discordance of databases designed for claims payment versus clinical information systems: implications for outcomes research. Annals of Internal Medicine 1993, 119(8):844-850.

27. Tang PC, Ralston M, Arrigotti MF, Qureshi L, Graham J: Comparison of methodologies for calculating quality measures based on administrative data versus clinical data from an electronic health record system: implications for performance measures. Journal of the American Medical Informatics Association 2007, 14(1):10-15.

28. Freeman R, Moore L, García Álvarez L, Charlett A, Holmes A: Advances in electronic surveillance for healthcare-associated infections in the 21st Century: a systematic review. Journal of Hospital Infection 2013.

29. Bates DW, Gawande AA: Improving safety with information technology. New England Journal of Medicine 2003, 348(25):2526-2534.

30. Jha AK, Doolan D, Grandt D, Scott T, Bates DW: The use of health information technology in seven nations. International journal of medical informatics 2008, 77(12):848-854.

31. Jha AK, DesRoches CM, Kralovec PD, Joshi MS: A progress report on electronic health records in US hospitals. Health Affairs 2010, 29(10):1951-1957.

32. Chan KS, Fowles JB, Weiner JP: Review: electronic health records and the reliability and validity of quality measures: a review of the literature. Medical Care Research and Review 2010, 67(5):503-527.

33. National Healthcare Safety Network (NHSN) Annual Reports. [http://www. cdc.gov/nhsn/datastat.html].

34. Hannan EL, Cozzens K, King III SB, Walford G, Shah NR: The New York State Cardiac Registries. Journal of the American College of Cardiology 2012, $59(25)$.
35. Pham JC, Gianci S, Battles J, Beard P, Clarke JR, Coates H, Donaldson L, Eldridge N, Fletcher M, Goeschel CA: Establishing a global learning community for incident-reporting systems. Quality and Safety in Health Care 2010, 19(5):446-451.

36. Nuckols TK, Bell DS, Liu H, Paddock SM, Hilborne LH: Rates and types of events reported to established incident reporting systems in two US hospitals. Quality and Safety in Health Care 2007, 16(3):164-168.

37. Levtzion-Korach O, Frankel A, Alcalai H, Keohane C, Orav J, Graydon-Baker E, Barnes J, Gordon K, Puopulo AL, Tomov El: Integrating incident data from five reporting systems to assess patient safety: making sense of the elephant. Joint Commission Journal on Quality and Patient Safety 2010, 36(9):402-410.

38. Weingart SN, Pagovich O, Sands DZ, Li JM, Aronson MD, Davis RB, Bates DW, Phillips RS: What Can Hospitalized Patients Tell Us About Adverse Events? Learning from Patient-Reported Incidents. Journal of General Internal Medicine 2005, 20(9):830-836.

39. Weissman JS, Schneider EC, Weingart SN, Epstein AM, David-Kasdan J, Feibelmann S, Annas CL, Ridley N, Kirle L, Gatsonis C: Comparing patientreported hospital adverse events with medical record review: do patients know something that hospitals do not? Annals of Internal Medicine 2008, 149(2):100-108.

40. Localio AR, Lawthers AG, Brennan TA, Laird NM, Hebert LE, Peterson LM, Newhouse JP, Weiler PC, Hiatt HH: Relation between malpractice claims and adverse events due to negligence: results of the Harvard Medical Practice Study III. New England Journal of Medicine 1991, 325(4):245-251.

41. Rubin HR, Pronovost P, Diette GB: The advantages and disadvantages of process-based measures of health care quality. International Journal for Quality in Health Care 2001, 13(6):469-474.

42. Hawn MT, Itani KM, Gray SH, Vick CC, Henderson W, Houston TK: Association of timely administration of prophylactic antibiotics for major surgical procedures and surgical site infection. Journal of the American College of Surgeons 2008, 206(5):814-819.

43. Shahian DM, Meyer GS, Mort E, Atamian S, Liu X, Karson AS, Ramunno LD, Zheng $\mathrm{H}$ : Association of National Hospital Quality Measure adherence with long-term mortality and readmissions. BMJ Quality \& Safety 2012, 21(4):325-336.

44. Leape LL, Berwick DM, Bates DW: What practices will most improve safety? JAMA: the journal of the American Medical Association 2002, 288(4):501-507.

45. Lagasse RS: Anesthesia Safety: Model or Myth?: a review of the published literature and analysis of current original data. Anesthesiology 2002, 97(6):1609-1617.

46. Oren E, Shaffer ER, Guglielmo BJ: Impact of emerging technologies on medication errors and adverse drug events. American Journal of HealthSystem Pharmacy 2003, 60(14):1447-1458.

47. Fletcher KE, Davis SQ, Underwood W, Mangrulkar RS, McMahon LF, Saint S: Systematic review: effects of resident work hours on patient safety. Annals of Internal Medicine 2004, 141(11):851-857.

48. Auerbach AD, Landefeld CS, Shojania KG: The tension between needing to improve care and knowing how to do it. New England Journal of Medicine 2007, 357(6):608.

49. Shekelle PG, Pronovost PJ, Wachter RM, Taylor SL, Dy SM, Foy R, Hempel S, McDonald KM, Ovretveit J, Rubenstein LV: Advancing the science of patient safety. Annals of Internal Medicine 2011, 154(10):693-696.

50. Landrigan CP, Parry GJ, Bones CB, Hackbarth AD, Goldmann DA, Sharek PJ: Temporal trends in rates of patient harm resulting from medical care. New England Journal of Medicine 2010, 363(22):2124-2134.

51. Romano PS, Geppert JJ, Davies S, Miller MR, Elixhauser A, McDonald KM: A national profile of patient safety in US hospitals. Health Affairs 2003, 22(2):154-166.

52. Rosen AK, Zhao S, Rivard P, Loveland S, Montez-Rath ME, Elixhauser A, Romano PS: Tracking rates of Patient Safety Indicators over time: lessons from the Veterans Administration. Medical care 2006, 850-861.

53. Downey JR, Hernandez-Boussard T, Banka G, Morton JM: Is Patient Safety Improving? National Trends in Patient Safety Indicators: 1998-2007. Health Services Research 2012, 47(1pt2):414-430.

54. Vogel TR, Dombrovskiy VY, Lowry SF: Trends in postoperative sepsis: are we improving outcomes? Surgical infections 2009, 10(1):71-78.

55. Bateman BT, Schmidt U, Berman MF, Bittner EA: Temporal trends in the epidemiology of severe postoperative sepsis after elective surgery: a large, nationwide sample. Anesthesiology 2010, 112(4):917-925. 
56. Dimick JB, Nicholas LH, Ryan AM, Thumma JR, Birkmeyer JD: Bariatric Surgery Complications Before vs After Implementation of a National Policy Restricting Coverage to Centers of ExcellenceComplications Following Bariatric Procedures. JAMA 2013, 309(8):792-799.

57. Anderson FA, Hirsh J, White K, Fitzgerald RH: Temporal Trends in Prevention of Venous Thromboembolism Following Primary Total Hip or Knee Arthroplasty 1996-2001 Findings From the Hip and Knee Registry. CHEST Journal 2003, 124(6_suppl):349S-356S

58. Boltuch J, Sabeti S, Amighi J, Dick P, Mlekusch W, Schlager O, Ahmadi A, Minar E, Schillinger M: Procedure-related complications and early neurological adverse events of unprotected and protected carotid stenting: temporal trends in a consecutive patient series. Journal of Endovascular Therapy 2005, 12(5):538-547.

59. Rogers WJ, Canto JG, Lambrew CT, Tiefenbrunn AJ, Kinkaid B, Shoultz DA, Frederick PD, Every N: Temporal trends in the treatment of over 1.5 million patients with myocardial infarction in the U.S. from 1990 through 1999 The National Registry of Myocardial Infarction 1, 2 and 3. Journal of the American College of Cardiology 2000 36(7):2056-2063.

60. Jencks SF, Huff ED, Cuerdon T: Change in the quality of care delivered to Medicare beneficiaries, 1998-1999 to 2000-2001. JAMA: the journal of the American Medical Association 2003, 289(3):305-312.

61. Williams SC, Schmaltz SP, Morton DJ, Koss RG, Loeb JM: Quality of care in US hospitals as reflected by standardized measures, 2002-2004. New England Journal of Medicine 2005, 353(3):255-264.

62. Fridkin SK, Kaufman D, Edwards JR, Shetty S, Horan T: Changing incidence of Candida bloodstream infections among NICU patients in the United States: 1995-2004. Pediatrics 2006, 117(5):1680-1687.

63. Burton DC, Edwards JR, Horan TC, Jernigan JA, Fridkin SK: Methicillinresistant Staphylococcus aureus central line-associated bloodstream infections in US intensive care units, 1997-2007. JAMA: the journal of the American Medical Association 2009, 301(7):727-736.

64. Clark SL, Belfort MA, Byrum SL, Meyers JA, Perlin JB: Improved outcomes, fewer cesarean deliveries, and reduced litigation: results of a new paradigm in patient safety. American Journal of Obstetrics and Gynecology 2008, 199(2):105.e101-105.e107.

65. Berenholtz SM, Pronovost PJ, Lipsett PA, Hobson D, Earsing K, Farley JE, Milanovich S, Garrett-Mayer E, Winters BD, Rubin HR: Eliminating catheterrelated bloodstream infections in the intensive care unit*. Critical care medicine 2004, 32(10):2014-2020.

66. Pronovost PJ, Marsteller JA, Goeschel CA: Preventing bloodstream infections: a measurable national success story in quality improvement Health Affairs 2011, 30(4):628-634.

67. Peterson ED, Lansky AJ, Anstrom KJ, Muhlbaier LH, Popma JJ, Satler LF, Lanzilotta MJ: Evolving trends in interventional device use and outcomes: results from the National Cardiovascular Network Database. American Heart Journal 2000, 139(2):198-207.

68. Van Klei W, Hoff R, Van Aarnhem E, Simmermacher R, Regli L, Kappen T, van Wolfswinkel L, Kalkman C, Buhre W, Peelen L: Effects of the introduction of the WHO "Surgical Safety Checklist" on in-hospital mortality: a cohort study. Annals of surgery 2012, 255(1):44-49.

69. Muscedere J, Rewa O, Mckechnie K, Jiang X, Laporta D, Heyland DK: Subglottic secretion drainage for the prevention of ventilator-associated pneumonia: A systematic review and meta-analysis*. Critical care medicine 2011, 39(8):1985-1991.

70. Mehrotra A, Damberg CL, Sorbero ME, Teleki SS: Pay for performance in the hospital setting: what is the state of the evidence? American Journal of Medical Quality 2009, 24(1):19-28.

71. Glickman SW, Ou F-S, DeLong ER, Roe MT, Lytle BL, Mulgund J, Rumsfeld JS, Gibler WB, Ohman EM, Schulman KA: Pay for performance, quality of care, and outcomes in acute myocardial infarction. JAMA: the journal of the American Medical Association 2007, 297(21):2373-2380.

72. Mehrotra A, Sloss EM, Hussey PS, Adams JL, Lovejoy S, SooHoo NF: Evaluation of Centers of Excellence Program for Knee and Hip Replacement. Medical care 2013, 51(1):28-36.

73. Horwitz LI, Kosiborod M, Lin Z, Krumholz HM: Changes in outcomes for internal medicine inpatients after work-hour regulations. Annals of Internal Medicine 2007, 147(2):97-103.

74. Shulkin DJ: Like Night and Day - Shedding Light on Off-Hours Care. New England Journal of Medicine 2008, 358(20):2091-2093.
75. Jagsi R, Kitch B, Weinstein DF, Campbell EG, Hutter M, Weissman JS: Residents report on adverse events and their causes. Archives of Internal Medicine 2005, 165(22):2607-2613.

76. Härkänen $M$, Turunen $H$, Saano S, Vehviläinen-Julkunen K: Medication errors: what hospital reports reveal about staff views. Nursing management (Harrow, London, England: 1994) 2013, 19(10):32-37.

77. Cho S-H, Ketefian S, Barkauskas VH, Smith DG: The effects of nurse staffing on adverse events, morbidity, mortality, and medical costs. Nursing research 2003, 52(2):71-79.

78. Bell CM, Redelmeier DA: Mortality among patients admitted to hospitals on weekends as compared with weekdays. New England Journal of Medicine 2001, 345(9):663-668.

79. Aylin P, Yunus A, Bottle A, Majeed A, Bell D: Weekend mortality for emergency admissions. A large, multicentre study. Quality and Safety in Health Care 2010, 19(3):213-217

80. Perez-Concha O, Gallego B, Hillman K, Delaney G, Coiera E: Mortality Patterns vary across different patient groups following weekend admission: Reduced quality of care or a different patient cohort mix? BMJ Quality \& Safety 2013, doi: 10.1136/bmjqs-2013-002218.

81. Becker DJ: Do Hospitals Provide Lower Quality Care on Weekends? Health Services Research 2007, 42(4):1589-1612.

82. Saposnik G, Baibergenova A, Bayer N, Hachinski V: Weekends: a dangerous time for having a stroke? Stroke 2007, 38(4):1211-1215.

83. Kostis WJ, Demissie K, Marcella SW, Shao Y-H, Wilson AC, Moreyra AE: Weekend versus weekday admission and mortality from myocardial infarction. New England Journal of Medicine 2007, 356(11):1099-1109.

84. Aujesky D, Jiménez D, Mor MK, Geng M, Fine MJ, Ibrahim SA: Weekend versus weekday admission and mortality after acute pulmonary embolism. Circulation 2009, 119(7):962-968.

85. Pasupathy D, Wood AM, Pell JP, Fleming M, Smith GC: Time of birth and risk of neonatal death at term: retrospective cohort study. BMJ: British Medical Journal 2010, 341

86. Gould JB, Qin C, Chavez G: Time of birth and the risk of neonatal death Obstetrics \& Gynecology 2005, 106(2):352-358.

87. Bell CM, Redelmeier DA: Waiting for urgent procedures on the weekend among emergently hospitalized patients. The American journal of medicine 2004, 117(3):175-181

88. Hendey GW, Barth BE, Soliz T: Overnight and postcall errors in medication orders. Academic emergency medicine 2005, 12(7):629-634.

89. Magid DJ, Wang Y, Herrin J, McNamara RL, Bradley EH, Curtis JP, Pollack CV French WJ, Blaney ME, Krumholz HM: Relationship between time of day, day of week, timeliness of reperfusion, and in-hospital mortality for patients with acute ST-segment elevation myocardial infarction. JAMA: the journal of the American Medical Association 2005, 294(7):803.

90. Vogel TR, Dombrovskiy VY, Lowry SF: In-hospital delay of elective surgery for high volume procedures: the impact on infectious complications. Journal of the American College of Surgeons 2010, 211(6):784-790.

91. Moja L, Piatti A, Pecoraro V, Ricci C, Virgili G, Salanti G, Germagnoli L, Liberati A, Banfi G: Timing matters in hip fracture surgery: patients operated within 48 hours have better outcomes. A meta-analysis and meta-regression of over 190,000 patients. PloS one 2012, 7(10):e46175

92. Aylin P, Alexandrescu R, Jen MH, Mayer EK, Bottle A: Day of week of procedure and 30 day mortality for elective surgery: retrospective analysis of hospital episode statistics. BMJ 2013, 346.

93. Zare MM, Itani KM, Schifftner TL, Henderson WG, Khuri SF: Mortality after nonemergent major surgery performed on Friday versus Monday through Wednesday. Annals of surgery 2007, 246(5):866-874.

94. Peberdy MA, Ornato JP, Larkin GL, Braithwaite RS, Kashner TM, Carey SM Meaney PA, Cen L, Nadkarni VM, Praestgaard AH: Survival from in-hospital cardiac arrest during nights and weekends. JAMA: the journal of the American Medical Association 2008, 299(7):785-792.

95. Laupland KB, Shahpori R, Kirkpatrick AW, Stelfox HT: Hospital mortality among adults admitted to and discharged from intensive care on weekends and evenings. Journal of critical care 2008, 23(3):317-324.

96. Young JQ, Ranji SR, Wachter RM, Lee CM, Niehaus B, Auerbach AD: "July Effect": Impact of the Academic Year-End Changeover on Patient OutcomesA Systematic Review. Annals of Internal Medicine 2011, 155(5):309-315.

97. Huckman RS, Barro J: Cohort turnover and productivity: the July phenomenon in teaching hospitals. National Bureau of Economic Research 2005 . 
98. Barker GE: A July spike in fatal medication errors: a possible effect of new medical residents. Journal of General Internal Medicine 2010, 25(8):774-779.

99. [http://www.patientcarelink.org/].

doi:10.1186/2047-2501-3-S1-S2

Cite this article as: Gallego et al: Insights into temporal patterns of hospital patient safety from routinely collected electronic data. Health Information Science and Systems 2015 3(Suppl 1):S2.

Submit your next manuscript to BioMed Central and take full advantage of:

- Convenient online submission

- Thorough peer review

- No space constraints or color figure charges

- Immediate publication on acceptance

- Inclusion in PubMed, CAS, Scopus and Google Scholar

- Research which is freely available for redistribution

Submit your manuscript at www.biomedcentral.com/submit 